\title{
Analisis Faktor Lingkungan Bisnis Ritel Berbasis Swalayan \\ Pada Lab. Bisnis
}

\author{
Oleh: \\ Mukaram dan Ira Siti Sarah
}

\begin{abstract}
Department of Business Administration has a business laboratory (Business Lab) that is based on retail business concept. Until now, the profit per year earned by the Business Lab is still below the average of other retail store business in the same industry. The condition is suspected by less attention to stores environmental factors that then have an impact on customer satisfaction. Competition among retail companies increasingly stringent push the owner to be more creative and innovative in creating marketing strategies. Retail business environment is one of the most important variables to be considered for the survival of a retail store. By knowing the dominant factors in the retail store environment variable, the store management can make more appropriate marketing strategies to attract customers and increase the customers satisfaction. This study aims to assess the environmental factors stores in Business Lab. The data collection is done by distributing 161 questionnaires to consumers of Business Lab. Data were analyzed using exploratory factor analysis (EFA). The result indicate there are three factors in the stores environment factors that need redefinition. First, the second factor was sugested to be renamed to promotions and convenience shopping after getting two new variables, namely direction and facilities. Secondly, the fourth factor is sugested to adjust its name to 'availability' as it contains two components, location and time of operation in the same factor. Third, the 'atmosphere of the shop' is divided into two different factors, namely 'convenience shopping' and 'storefront'.
\end{abstract}

Keywords: Shops environment, Customer satisfaction, Retail, Self-service.

\section{Pendahuluan}

Pelaksanaan aktivitas Lab. Bisnis yang ada pada jurusan Administrasi Niaga cenderung berbentuk kepada industri ritel berbasis swalayan. Keuntungan/laba bersih pada tahun 2013 lalu adalah sebesar Rp 14.783.930,-. Jumlah keuntungan per tahun ini berada di bawah rata-rata toko ritel lain dalam industri yang sama. Hal tersebut dicurigai oleh faktor lingkungan toko Lab. Bisnis yang kurang diperhatikan dan kemudian berdampak kepada kepuasan konsumen. Persaingan dalam bisnis ritel di Indonesia dapat dirasakan dengan munculnya ritel-ritel baru, baik itu ritel lokal maupun ritel asing. Suka atau tidak suka, saat ini setiap perusahaan berada dalam persaingan yang semakin ketat. Selain disebabkan oleh munculnya ritel-ritel baru, konsumen juga sudah semakin cerdas, sadar harga, banyak menuntut, kurang memaafkan dan memiliki banyak pilihanuntuk berbelanja.

Setiap perusahaan berusaha dan berlomba-lomba dengan berbagai cara untuk merebut hati pelanggan. Kotler, Hayes dan Bloom (2002) menyebutkan ada enam alasan mengapa perusahaan perlu mendapatkan kepuasan pelanggan:

1. Pelanggan yang loyal memberikan keuntungan besar bagi perusahaan. 
2. Biaya yang dikeluarkan untuk mendapatkan pelanggan baru jauh lebih besar dibandingkan mempertahankan pelanggan yang ada.

3. Pelanggan yang sudah percaya pada perusahaan dalam suatu urusan bisnis akan percaya juga dalam bisnis lainnya.

4. Biaya operasional akan lebih efisien.

5. Pelanggan sudah memiliki banyak pengalaman positif dengan perusahaan.

6. Pelanggan akan senantiasa membela perusahaan dan bahkan mampu menarik orang lain untuk menjadi pelanggan.

Kepuasan pelanggan merupakan faktor yang sangat penting bagi kelangsungan sebuah perusahaan. Pelanggan yang loyal secara aktif akan mempromosikan perusahaan dan memberikan rekomondasi kepada kerabat dan sahabat mereka, menjadikan perusahaan sebagai pilihan utama dan tidak mudah untuk berpindah ke kompetitor lain, serta menambah frekuensi pembelian pada perusahaan. Kepuasan pelanggan merupakan pengukuran kesenjangan antara harapan pelanggan dengan kenyataan yang mereka terima atau rasakan. Jika yang diterima oleh pelanggan sesuai dengan harapan atau melebihi harapan, maka pelanggan akan merasa puas atau sangat puas, namun jika tidak sesuai dengan harapan pelanggan akan merasa tidak puas. Ketidakpuasan ini terjadi karena adanya kesenjangan antara harapan dan kenyataan yang diterima oleh pelanggan. Jika puas pelanggan akan cenderung untuk kembali dan menjadi loyal.

Selain brand loyalty, Laudon dan Bitta (1993) mengenalkanstore loyalty sebagai salah satu perwujudan kepuasan konsumen. Pada tipe kepuasan ini, pelanggan loyal terhadap tokonya bukan pada produk. Pelanggan akan datang terus-menerus pada toko yang sama tanpa mempertimbangkan produk apa yang akan dibeli. Ini terjadi disebabkan, karena suasana toko, atribut toko, dan image dari toko.Kepuasan toko adalah salah satu faktor terpenting dalam menentukan kesuksesan suatu bisnis eceran dan keberlangsungan toko tersebut. Tanpa adanya kepuasan dalam suatu bisnis eceran, maka keunggulan kompetitif yang dimiliki seperti tidak pernah ada dan tidak akan sukses (Omar 1999).

Dengan semakin cerdasnya konsumen saat ini, harga bukan lagi menjadi pertimbangan utama konsumen dalam memilik sebuah produk. Konsumen sekarang lebih banyak melihat dari segi nilai atau manfaat yang ditawarkan dari sebuah produk. Nilai disini merupakan kombinasi dari harga, kualitas, layanan purnajual, pengalaman yang berkesan, dan sebagainya (Irawan. 2002). Atas dasar tersebut,maka penting untuk Lab. Bisnis mengetahui faktor-faktor yang dapat membuat konsumen menjadi loyal terhadap Lab. Bisnis.Dengan mengetahui faktor-faktor yang dominan di mata konsumen,manajemen dapat meningkatkan faktor-faktor tersebut dan membuat strategi yang lebih sesuai untuk menarik pelanggan dan menjadikan pelanggan tersebut loyal terhadap perusahaan. Berdasarkan uraian di atas, maka peneliti tertarik untuk melakukan penelitian tentang "Analisis Faktor Lingkungan Bisnis Ritel Berbasis Swalayan pada Lab. Bisnis”.

\section{Perumusan Masalah}

Dari uraian latar belakang yang telah dikemukakan diatas, maka dapat dirumuskan permasalahan sebagai berikut :

a. Berapa jumlah faktor yang dapat dibentuk dari variabel-variabel faktor lingkungan Lab. Bisnis?

b. Apa saja faktor-faktor yang dipertimbangkan konsumen dalam menilai lingkungan Lab. Bisnis? 
Variabel yang diteliti hanya terkait dengan manajemen pemasaran dan manajemen organisasi. Penelitian yang dilakukan kepada mahasiswa, dan masyarakat konsumen Lab. Bisnis berbasis ritel yang ada di Jurusan Administrasi Niaga.

\section{Tinjauan Pustaka}

\section{a. Evaluasi Konsumen}

Konsumen adalah salah satu unsur penting dalam proses jual beli. Menurut Kotler dan Armstrong (2009), konsumen adalah setiap orang pemakai barang dan atau jasa yang tersedia dalam masyarakat, baik bagi kepentingan diri sendiri, keluarga, orang lain, maupun makhluk hidup lain dan tidak untuk diperdagangkan. Dalam menjalankan bisnis jual beli barang atau jasa, perusahaan haruslah memiliki citra yang baik di depan konsumen.

Dalam kaitanya dengan lingkungan toko, evaluasi konsumen haruslah dipertimbangkan. Konsumen akan mengevaluasi keadaan toko yang sudah dilihatnya. Menurut Archana Kumar (2010) terdapat unsur organism dalam proses evaluasi konsumen. Bagozzi (dalam Kumar, 2010) mendefinisikan organism sebagai "the internal processes and structures intervening between stimuli external to the person and the final actions, reactions, or responses emitted".

Menurut Archana Kumar (2010) salah satu dari proses evaluasi konsumen dalam organism yaitu cognitive evaluation. Cognitive evaluation menurut Bettman dan Zeithaml (dalam Kumar, 2010) adalah "associated with consumer perception process, which originates from information-procesing and inference theories". Persepsi adalah aktivitas fisiologis di mana isyarat stimulasi sensorik diubah menjadi informasi yang bermakna. Isyarat lingkungan toko akan memberikan beberapa informasi penting berdasarkan penglihatan dan perasaan kosumen yang akan memperoleh kesimpulan tentang harga, produk, kualitas, dan pelayanan di toko itu. Misalnya, penggunaan karpet mewah dalam desain toko dapat membuat konsumen menyimpulkan bahwa toko mungkin menetapkan harga yang lebih tinggi dan memberikan kualitas barang dan layanan yang tinggi. Kesimpulan rasional seperti ini berdasarkan isyarat lingkungan termasuk ke dalam evaluasi kognitif. Dengan demikian lingkungan toko sangatlah menentukan cognitive evaluation dari konsumen.

\section{b. Store Environment dalam Konsep Retailing Mix}

Dalam usaha menjalankan retail strategy, konsep pemasaran mengembangkan retailing mix untuk memuaskan kebutuhan dan keinginan konsumnennya, dimana retailing mix merupakan kombinasi dari faktor-faktor yang digunakan retailer untuk memuaskan konsumen dan mempengaruhi keputusan pembeliannya.

Menurut Widya Utami (2006:239), retailing mix adalah kombinasi dari elemenelemen yang digunakan oleh pengecer untuk memuaskan kebutuhan konsumen dan mempengaruhi keputusan pembelian mereka. Elemen-elemen dari retailing mix meliputi: barang dan jasa yang ditawarkan, penentuan harga, program promosi dan periklanan, suasana toko, pelayanan pelanggan, dan lokasi.

\section{c. Elemen-Elemen Store Environment}

Store environment dapat didefinisikan sebagai kesadaran dalam merancang ruangan untuk menciptakan efek-efek tertentu pada pembeli. Lebih khusus lagi, store environment adalah upaya untuk merancang lingkungan pembelian untuk menghasilkan efek emosional tertentu pada pengunjung toko yang dapat meningkatkan kemungkinan pembeliannya (McGoldrick, 2003: 459). Berdasarkan definisi diatas penataan store environment adalah 
suatu usaha yang dilakukan perusahaan untuk mendesain tokonya dengan berbagai cara agar dapat terlihat indah dan dapat menarik perhatian konsumen.

Untuk menciptakan store environment yang menarik dan kreatif yaitu dengan mendesain bagian depan toko dengan menarik, menciptakan suatu suasana toko yang nyaman dan mendesain interior secara kreatif sehingga dapat membujuk konsumen potensial untuk masuk dedalam toko, melihat-lihat dan dengna harapan terjadinya proses pembelian. Dunne dan Lusch (2005: 450) membagi store environment menjadi empat elemen utama, yaitu:

\section{1) Store Planning}

a) Allocating Space.

Dalam mengalokasikan ruangan, bagian-bagian yang harus diperhatikan meliputi:

- Back Room

Ruangan belakang berfungsi sebagai tempat keluar masuknya barangbarang dagangan, perlengkapan toko, dan perlalatan yang digunakan di toko. Ruangan belakang juga meliputi tempat menyimpna stok barang.

- Office and Functional Space

Kantor dan ruangan fungsional meliputi ruang istirahat, kantor dan kamar mandi.

- Aisles, and Service Areas

Gang diantara display harus dubuat cukup besar agar konsumen tidak saling bersenggolan. Toko juga harus menyediakan tempat pelayanan konsumen dan area dimana tidak terdapat display.

- Floor Merchandise Space

Ruangan penyajian barang harus dibuat semenarik dan seefisien mungkin. Display dan fixture harus memudahkan konsumen untuk memperoleh barang.

- Wall Merchandise Space

Tembok ini berfungsi sebagai tempat menggantungkan display dan fixture, oleh karena itu tembok ini harus dibuat kokoh agar kuat menahan display dan fixture.

\section{b) Circulation}

Suatu pola sirkulasi tidak hanya menciptakan jalur yang dilalui pengunjung dengan efisien, membawa mereka melihat seluruh barnag, tetapi juga membentuk karakter dari toko tersebut. Ada empat bentuk dasar dari pola sirkualsi, yaitu:

- Free flow layout

Pola yang paling sederhana dimana fixture dan barang-barang diletakkan secara bebas. Pola ini cocok untuk toko dengan ukuran kecil dan jenis barang yang sama.

- Grid layout

Penempatan counter dan fixtures dalam satu lorong utama yang panjang. Pada satu counter ditempatkan barang dengan kategori yang sama, 
sehingga pengunjung dapat dengan mudah mencari barang yang dibutuhkan.

- Loop layout

Terdiri dari gang-gang utama yang dimulai dari pintu masuk mengelilingi seluruh ruangan dan biasanya berbentuk lingkaran atau persegi, kemudian kembali ke pintu masuk, sepanjang jalan konsumen dapat melihat dan mengerti barang-barang dagangan tersebutdengan mudah.

- Spine layout

Pada dasarnya merupakan variasi dan menggabungkan kelebihankelebihan dari ketiga layout diatas. Pada spine layout, gang utama terbentang dari depan sampai belakang toko. Membawa pengunjung dalam dua arah, pada kedua sisi terbagi dua barang-barang yang diletakkan seperti dalam grid layout atau free flow layout.

\section{c) Shrinkage Prevention}

Ketika merencanakan layout dan desain toko. Perlu dipikirkan mengenai pencegahan penyusutan barang yang diakibatkan oleh pencurian, kerusakan dan kehilangan. Untuk barang-barang dengan ukuran kecil harus disimpan di dalam etalase atau di tempat-tempat yang dapat diawasi, karena barang-barang dengan berukuran kecil ini adalah paling rentan terhadap pencurian.

\section{2) Merchandising}

Memilih peralatan penunjang dan cara menyusun barang harus dengan baik agar di dapat hasil yang sesuai dengan keinginan, kearena barang-barang tersebut berbeda bentuk, karakter maupun harganya, sehingga penempatannya pun berbeda. Menurut Berman dan Evans (2007: 546) menjajakan barang adalah suatu aktivitas yang mencakup penyediaan barang atau jasa khusus dan membuat mereka tersedia pada tempat, waktu dan harga dan juga dalam jumlah yang memungkinkan retailer untuk mencapai tujuannya. Dengan bantuan peralatan penunjang dan dengan cara penyusunan yang berbeda dapat diciptakan kesan atau image yang berbeda pula. Dunne dan Lusch (2005: 468) mengemukakan tipe-tipe fixtures sebagai berikut:

a) Hardline Fix

Rak-rak yang besar dan berat, dapat dilengkapi dengan laci dan gantungan, cocok utnuk barang-barang ukuran besar dan dalam jumlah yang banyak.

b) Soft line Fix

Berupa gantungan dengan berbagai bentuk sesuai dengan kebutuhan.

c) Wall fix

Rak atau peralatan yang didesain utnuk meletakan barang di dinding, wall fisx cocok unti meletakan beberapa barang yang dikombinasi untuk memberikan contoh pemakaian pada konsumen.

Untuk menyajikan barang (merchandise presentation) terdapat enam metode yang dapat digunakan. Metode-metode tersebut adalah:

a) Shelving, yaitu menyususn barang-barang dalam laci atau rak.

b) Hanging, menggantuk pakaian pada rak gantungan. 
c) Pegging, barang-barang yang kecil, seperti aksesoris wanita digantung pada sejenis paku, bisa terdapat di dinding atau rak yang besar.

d) Stacking, menumpuk barang dalam rak untuk memberi kesan berlimpah.

e) Dumping, meletakan barang-barang kecil dan berjumlah banyak dalam keranjang, hal ini dapat memberikan kesan barang tersebut murah dan melimpah

f) Folding, melipat barang-barang yang berjenis kain dan diletakan pada rak maupun di atas meja.

\section{3) Store Design}

Dunne dan Lusch $(2005 ; 473)$ mengemukakan bahwa: "Store design is the element most responsible for the first of our two goals in planning the store environment: Crating a distinctive and memorable store image. Store design encompasses both the exterior and the interior of the store."

Dari pernyataan di atas dapat dikatakan bahwa store design adalah elemen yang paling bertanggung jawab dalam mencapai tujuan dari perencanaan lingkungna toko, yaitu menciptakan kesan toko yang khusus dan juga selalu diingan ingant. Store design meliputi:

a) Storefront Design

Bagian depan toko harus secara jelas memperkenalkan nama toko, suasana dan memberi gambaran tentang barang-barang yang ada di dalam toko. Bagian depan toko meliputi exterior signage, arsitektur dan jendela etalase di depan toko.

b) Interior Design

Elemen-elemen dari interior design adalah:

- The finished applied to the surface, adalah pemilihan material yang digunakan dalam melapisi lantai, dinding atau langit-langit toko dengan menggunakan kayu, karpet, keramik atau marmer. Tiap-tiap bahan ini mempunyai kesan yang berbeda-beda bagi konsumen. Sebagai contoh, penggunaan marmer pada lantai toko menciptakan kesan menengah keatas, eksklusif dan mahal.

- The Architectural Shapes, adalah menggunakan berbagai macam bentuk pada desain interiornya. Misalnya pada bentuk display, etalase, meja karsi, dan sebagainya.

c) Lightning Design, baik dari pencahayaan luar toko, di dalam toko, pada etalase, pada display dan lain-lain. Tehnik pencahayaan yang baik bisa mempengaruhi suasana hati dari pengunjung yang datang. Sebagai contoh, bila suasana tokonya tenang dan cahayanya pas dan sesuai, para pengunjung toko akan merasa tenang dan betah berlama-lama berada di dalam toko.

d) Sound and Smell, karena desain toko yang efektif adalah desain yang dapat menarik atau mempengaruhi emosi konsumen melalui penglihatan, pendengaran, penciuman dan sentuhan. Musik, airconditioner dan aroma wangi ruangan menjadi elemen yang paling utama.

\section{4) Visual Communication}

Visual communication bisa dilakukan dengan menggabungkan lambing-lambang, poster/gambar denga ukuran besar, dan alat visual lainnya yang bisa berperan 
sebagai 'pelayan toko bisu'. Visual communication menyediakan informasi dan arahan bagi pelanggan untuk berbelanja. Visual communication ini meliputi:

a) Name, Logo, and Retail Identity

Identitas toko terdiri atas nama toko, logo dan elemen visual lainnya. Nama dan logo ini harus menarik, mudah diingant, membuat penasaran, dan yang terpenting adalah mencerminkan jenis barang yang dijual di dalam toko.

b) Institutional Signage

Signage ini biasanya diletakan di pintu masuk toko untuk menyambut pelanggan yang masuk kedalam toko. Institutional signage ini meliputi meja atau kursi.

Directional, Departemental, and Cagegoty Signage Signage ini berfungsi untik membantu memberikan informasi dan mengarahkan konsumen ke tiaptiap departemaent, sehingga memudahkan konsumen untuk menemukan barang-barang yang mereka butuhkan.

c) Point of Sale (POS) Signage

Signage ini biasanya berbentuk kartu ukuran kecil yang berisi penjelasan tentang prosuk. Sistem point of sale (POS) adalah satu system perangkat teknologi yang merespons tuntutan praktis dar setiap transaksi. Elemen yang berada di area kasir ini terdiri dari layar monitor, keyboard, scanner, cash drawer, tempat menggesekkan keru kredit dan debet, dan lain-lain.

d) Lifestyle Graphics

Grafis ini biasanya berupa poster/gambar/foto, artistic mengenai barangbarang yang dijual di toko dengan tujuan untuk mempengaruhi konsumen dan melakukan pembelian. Grafis ini juga biasanya adalah foto-foto dari selebriti yang memakai produk produk dari toko tersebut.

Sedangkan dalam penelitian yang dilakukan oleh Kumar (2010) yang berjudul "The Impact of Store Environment on Consumer Evalauation and Behaviour toward Single-Brand Apparel Retailers". Elemen-elemen yang terdapat di dalam store environment meliputi tiga elemen yaitu sosial cues, design cues, and ambient cues.

\section{1) Social Cues}

Social cues (isyarat sosial) dalam lingkungan toko menurut Baker, Grewal, \& Parasuraman (1994); Machleit, Kellrais, \& Erogulu (1994); Singh (2006), dalam Kumar (2010) mencakup kecukupan jumlah karyawan, penampilan karyawan, keramahan karyawan, pengetahuan karyawan, pakaian yang dikenakan karyawan, tingkah laku karyawan, suasana toko, pelayanan pengunjung, dan keadaan pengunjung di toko.

2) Design Cues

Design cues (isyarat desain) dalam lingkungan toko menurut Baker, Grewal, \& Parasuraman (1994); Singh (2006) dalam Kumar (2010) mencakup layout yang diterapkan di toko, warna-warna yang digunakan di toko, keatraktifan fasilitas fisik toko, keterorganisiran penempatan barang di toko, kesusuaian penempatan barang, kemudahan toko untuk dijelajahi, kecukupan ruang gerak di toko, dan peneonjolan produk dalam dekorasi. 


\section{3) Ambient Cues}

Ambient cues (isyarat lingkungan) dalam lingkungan toko menurut Baker, Grewal, \& Parasuraman (1994); Singh (2006); Singh (2006) dalam Kumar (2010) mencakup pencahayaan di toko, latar belakang musik di toko yang menarik, tidak mengganggu, dan susuai dengan situasi berbelanja.

\section{Pelayanan dan Harga dalam Konsep Marketing Mix}

Kotler dan Armstrong (2006) mengatakan bahwa bauran pemasaran(marketing mix) meliputi diantaranya adalah: product/serivce, price, promotion and place. Penentuan semua unsur tersebut akan sangat berpengaruh kepada keputusan konsumen, dan pada akhirnya berimplikasi kepada meningkatnya volume penjualan. Zeithaml dan Bitner dalam Hurriyati (2008), mengemukakan definisi bauran pemasaran sebagai berikut: "Marketing mix defined as the elements an organizations controls that can be used to satisfy or communicate with customer. These elements appear as core decisions variables in any marketing text or marketing plan". Sedangkan menurut Griffin (1999), bauran pemasaran itu adalah "gabungan strategi produk, penetapan harga, promosi dan distribusi yang digunakan untuk memasarkan produk-produk".

Faktor-faktor seperti kualitas produk, kualitas layanan, dan harga pada akhirnya akan mempengaruhi kepuasan pelanggan seperti yang terdapat dalam Gambar 1.

Seperti yang nampak dalam Gambar 1, faktor-faktor yang mempengaruhi tentang kepuasan pelanggan yaitu:

1) Kualitas pelayanan perusahaan yang bergerak di bidang jasa sangat tergantung pada kualitas jasa yang diberikan. Dalam perkembangan alat ukur kualitas pelayanan, Parasuraman, dkk (1998) mengemukakan bahwa sepuluh dimensi yang dikemukakan para ahli terdahulu dapat dirangkum menjadi lima dimensi pokok kualitas pelayanan yaitu:

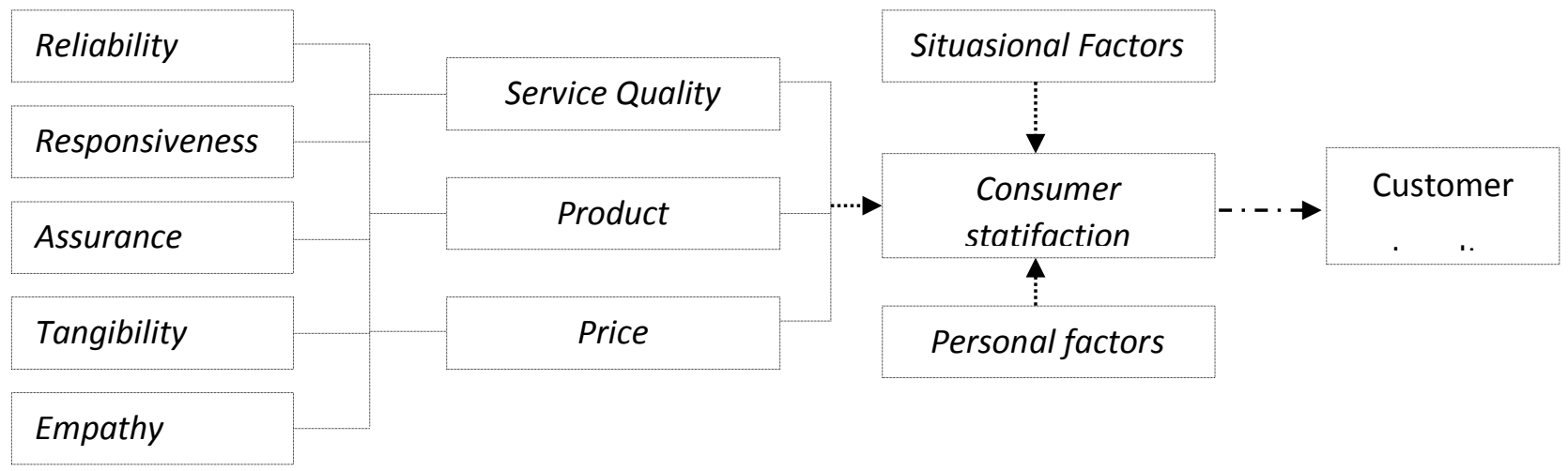

Gambar 1. Factor Influencing Customer Statification

Sumber: Zeithaml dan Bitner dalam Suhartanto (2001)

a) Reliability yaitu pelayanan dari penyedia jasa yang dapat diukur melalui kemampuan dalam memberikan pelayanan secara akurat dan dapat dipercaya ketika menyampaikan janji-janjinya mengenai penyampaian layanan dan penyelesaian masalah.

b) Responsivenes yaitu kemampuan dan kemauan pemberi layanan untuk membantu pelanggan/tamu dengan tepat (sesuai dengan kebutuhan pelanggan, juga memperhatikan waktu tunggu pelanggan untuk dilayani, menjawab pertanyaan atau perhatian terhadap masalah. 
c) Assurance yaitu pengetahuan dan kesopanan diukur melalui sikap ramah, senyim, kompetensi dan respek terhadap pelanggan yang datang dan dapat menimbulkan kepercayaan sehingga pelanggan percaya kepada pemberi layanan.

d) Tangibles yaitu penampilan diukur secara fisik yang berupa perlengkapan, peralatan, atau karyawan sebagi alat yang dapat mengembangkan layanan yang ditawarkan kepada pelanggan.

e) Empaty yaitu sikap menyenangkan yang dapat diukur dari ketika memberikan perlindungan, alternatif, perhatian yang individual melalui layanan yang disesuaikan dengan keinginan pelanggan.

2) Kualitas produk

Studi yang dilakukan di berbagai industri baik jasa maupun produk menunjukan arti penting faktor barang dalam mempengaruhi tingkat kepuasan konsumen (Kandampully dan Suhartanto, Aithaml dkk, dalam Suhartanto, 2001). Pada restoran fast food misalnya, kualitas makanan menjadi salah satu faktor utama yang paling banyak diperhatikan. Kualitas barang yang diberikan bersama-sama dengan pelayanan akan mempengaruhi persepsi konsumen terhadap pelayanan yang diterima. Sebaliknya barang yang kurang berkualitas akan merusak kepuasan konsumen secara keseluruhan.

Harga juga merupakan salah satu dari unsurmarketing mix. Kotler dan Armstrong (2006) menyatakan bahwa harga adalah sejumlah uang yang dibebankan atas suatu produk atau jasa, atau jumlah dari nilai yang di tukar konsumen atas manfaat-manfaat karena ingin memiliki atau menggunakan produk atau jasa tersebut. Harga merupakan nilai yang diberikan dari produk yang ditawarkan oleh perusahaan. Nilai disini tidak hanya mencakup nilai nominal dari suatu produk, tetapi nilai juga mencakup kualitas yang diterima konsumen. Dengan kata lain, harga harus mencerminkan kualitas dari produk yang ditawarkan. Harga produk digunakan untuk meningkatkan keuntungan, meningkatkan volume penjualan, meningkatkan gengsi perusahaan dan sebagai alat untuk bersaing.

Pembeli biasanya memandang harga sebagai indikator dari kualitas suatu jasa (Zeithaml, Solomon dalam Suhartanto, 2001) dalam restoran fast food faktor harga akan sangat berpengaruh dikarenakan antara penghantaran produk dan kualitas layanan dilakukan terstandarisasi sehingga konsumen biasanya berasumsi bahwa harga yang lebih tinggi mewakili kualitas yang tinggi (Barsky dalam Suhartanto, 2001). Diuraikan dengan lebih mendalam dalam bukunya, menurut Kotler dan Armstrong (2006) bahwa sebaiknya dalam menentukan sebuah harga, penjual harus mempertimbangkan beberapa hal sebagai berikut :

1) Harga tidak terlalu memperlihatkan biaya.

2) Harga diusahakan tidak sering berubah karena jika harga sering berubah akan mempengaruhi persepsi konsumen tentang harga tersebut.

3) Harga harus cukup bervariasi.

4) Harga bersaing dan sesuai dengan produk yang ditawarkan.

Dengan demikian harga merupakan salah satu hal terpenting dalam menentukan keputusan pembelian, maka dapat dipastikan bahwa apabila sudah merasa cocok dan sesuai antara harga dan kualitas yang ditawarkan maka tidak menutup kemungkinan konsumen akan tertarik pada produk tersebut, dan dengan harga yang konsisten maka konsumen bisa menjadi loyal terhadap produk ataupun merek. 
Berdasarkan atas studi pustaka (deductive thinking) yang telah dilakukan tersebut di atas, tersirat ada banyak sekali faktor yang bisa mempengaruhi loyalitas konsumen. Namun tidak diketahui secara pasti apakah keseluruhan faktor itu merupakan satu kesatuan faktor lingkungan yang mempengaruhi loyalitas konsumen atau sesuangguhnya merupakan konstruk-konstruk yang berbeda? Selain itu, tidak ada keterangan yang menjelaskan apakah faktor-faktor itu cukup untuk menguji loyalitas konsumen Lab. Bisnis? Berdasarkan hal-hal tersebut, penelitian ini akan menguji validitas faktor-faktor ini sebagai alat ukur faktor lingkungan yang dapat mempengaruhi loyalitas konsumen.

\section{Metodologi dan Rancangan Penelitian}

Studi dilakukan terhadap para pelanggan Lab.Bisnis Jurusan Administrasi Niaga, Politeknik Negeri Bandung. Penelitian menggunakan metode deskriptif dan verifikatif, hal ini dilakukan dalam bentuk analisis data primer dari hasil penyebaran kuesioner.

Sebelum dilakukan pengambilan data, peneliti terlebih dahulu melakukan pilot testing untuk mengetahui sejauh mana responden memahami kuesioner dari segi bahasa dan perintah. Setelah data terkumpul, peneliti melakukan pengolahan dan analisa data sebelum akhirnya data tersebut disusun untuk tahap pelaporan analisa data.

\section{Teknik Pengumpulan Data}

Teknik pengumpulan data yang digunakan adalah dengan menyebarkan kuesioner kepada pengunjung Lab.Bisnis yang berjumlah total 161 orang yang dipilih secara acak. Dalam pengisian kuesioner, responden didampingi oleh peneliti. Hal ini ditujukan untuk memastikan bahwa seluruh pertanyaan dalam kuesioner terisi secara lengkap oleh responden. Sebelum memberikan kuesioner, peneliti terlebih dahulu menanyakan kesediaan mereka untuk mengisi kuesioner. Hal ini dilakukan agar data yang nantinya diperoleh adalah data yang lebih akurat karena responden mengisi kuesioner tidak dalam keadaan terpaksa.

Teknik pengumpulan data merupakan suatu cara yang digunakan untuk mengumpulkan data. Mengingat data yang ingin diperoleh dalam penelitian ini diharapkan dapat mendukung pada keakuratan penelitian, untuk itu penulis menggunakan beberapa teknik pengumpulan data. Adapun teknik pengumpulan data yang dipergunakan penulis adalah sebagai berikut :

1) Penelitian Lapangan

Yaitu penelitian yang dilakukan dengan mengadakan peninjauan langsung terhadap objek yang diteliti, seperti penyebaran kuesioner. Hal ini merupakan pengumpulan data melalui penyebaran kuesioner yang berkaitan dengan variabelvariabel yang diteliti kepada pelanggan, untuk mengetahui tanggapan konsumen tentang faktor-faktor yang mendorong kepuasan konsumen terhadap Lab.Bisnis di Jurusan Administrasi Niaga.

2) Studi Kepustakaan

Merupakan pengumpulan data melalui laporan-laporan dan data-data yang ada kaitannya dengan masalah yang diteliti. Selain itu dalam pengumpulan data ini ditunjang dengan studi kepustakaan untuk memperoleh kajian teoritis yang berhubungan dengan teori-teori yang ada kaitannya dengan masalah dan variabel yang diteliti melalui sumber bacaan yang menunjang terhadap penelitian. 


\section{a. Jenis dan Sumber Data}

Sumber data yang digunakan dalam penelitian ini dibagi menjadi dua jenis, yaitu data primer dan data sekunder.

1) Data sekunder adalah data yang sebelumnya telah tersedia yang terdiri atas:

a) Studi kepustakaan dengan tujuan mencari referensi berupa teori-teori yang berkaitan dengan penelitian yang dibahas.

b) Artikel, majalah serta literatur lainnya yang berkaitan dengan penelitian.

2) Data primer yaitu data yang diperoleh langsung dari objek penelitian yaitu konsumen Lab.Bisnis.

a) Kuesioner yang digunakan adalah jenis kuesioner dengan pertanyaan tertutup.

b) Observasi yaitu pengamatan langsung pada objek sehingga diperoleh gambaran yang sebenarnya.

\section{b. Teknik Sampling}

Teknik sampling yang dilakukan oleh peneliti adalah teknik non probability sampling. Teknik ini digunakan karena jumlah populasi konsumen yang mengunjungi Lab.Bisnis cukup besar dan karena keterbatasan waktu, biaya dan tenaga.Menurut Sugiama (2008:120), non probability sampling merupakan penarikan sampel dari sebuah populasi yang didasarkan pada pertimbangan tertentu yang tidak membuka kemungkinan bagi semua individu dalam populasi dapat terpilih menjadi anggota sampel.Ada beberapa jenis non probability sampling, salah satunya adalah jenis yang digunakan dalam penelitian ini yaitu sistem convenience sampling. Menurut Sugiono (2003:83), convenience sampling yaitu sampel yang diambil secara acak. Alasan penggunaan metode convenience sampling adalah karena sampel yang digunakan dalam penelitian ini bukan berasal dari kelompok atau group tertentu. Kriteria sampel dalam penelitan ini adalah mereka yang berusia 15 tahun sampai 65 tahun yang pernah berbelanja atau mengunjungi Lab. Bisnis. Pada penelitian ini penulis mengambil sampel sebanyak 161 orang yang didasarkan pada pendapat Malhotra (2004:318) yang mengatakan ukuran sampel yang digunakan dalam Marketing Research Study biasanya digunakan sekitar 100-500 orang.

\section{c. Instrumen Penelitian}

Instrumen yang digunakan untuk penelitian ini adalah kuesioner. Kuesioner yang digunakan terdiri atas dua bagian. Bagian pertama berisikan tentang pertanyaan menganai profil responden, seperti jenis kelamin, umur, pekerjaan, penghasilan, dan pendapatan perbulan. Bagian dua berisikan pertanyaan tentang faktor-faktor lingkungan yang dipertimbangkan oleh konsumen saat mengunjungi Lab. Bisnis.

Penilaian kuesioner ini diukur berdasarkan skala likert 1 sampai 5, yaitu : nilai "1" berarti "Sangat Tidak Setuju (STS)", "2" berarti "Tidak Setuju (TS)", "3" berarti "Netral (N)", "4" berarti "Setuju (S)", dan "5" berarti "Sangat Setuju (SS)". Hal ini memungkinkan responden untuk memilih jawaban dan dari setiap pernyataan sesuai dengan pengalaman dan penilaian nasabah atas layanan atau jasa yang telah diterimanya.

\section{d. Rancangan Penelitian}

Dari hasil kajian pustaka yang telah dilakukan, maka didapatlah beberapa poin penting yang kemudian dijadikan sebagai operasional variabel seperti yang dijelaskan pada tabel dibawah ini. Indikator-indikator yang didapatkan sesuai dengan tinjauan pustaka yang berkaitan dengan penelitian yang dilakukan. 
Tabel 1. Operasionalisasi Variabel

\begin{tabular}{|c|c|c|c|}
\hline Variabel & Sub Variabel & Konsep Variabel & Indikator \\
\hline \multirow{6}{*}{$\begin{array}{l}\text { Lingkungan } \\
\text { Toko Lab } \\
\text { Bisnis }\end{array}$} & Lokasi & $\begin{array}{l}\text { Pada lokasi yang tepat, sebuah } \\
\text { gerai akan lebih sukses } \\
\text { dibandingkan gerai lainnya } \\
\text { yang berlokasi kurang } \\
\text { strategis, meskipun keduanya } \\
\text { menjual produk yang sama } \\
\text { (Ma'ruf, 2006:115). }\end{array}$ & $\begin{array}{l}\text { 1. Berada di lokasi yang biasa } \\
\text { dilewati } \\
\text { 2.Kemudahan menjangkau toko } \\
\text { 3. Kedekatan dengan lokasi } \\
\text { pertokoan } \\
\text { 4.Fasilitas yang memadai }\end{array}$ \\
\hline & Merchandise & $\begin{array}{l}\text { Merchandising } \\
\text { kegiatan pengadaan barang- } \\
\text { barang yang sesuai dengan } \\
\text { bisnis yang dijalani Toko } \\
\text { (produk berbasis makanan, } \\
\text { pakaian, barang kebutuhan } \\
\text { rumah, produk umum, dll, atau } \\
\text { kombinasi) untuk disediakan } \\
\text { dalam toko pada jumlah } \\
\text { waktu, dan harga yang sesuai } \\
\text { untuk mencapai sasaran toko } \\
\text { atau perusahaan ritel (Ma'ruf, } \\
\text { 2006:135). }\end{array}$ & $\begin{array}{l}\text { 5. Kualitas barang } \\
\text { 6. Variasi Merek } \\
\text { 7.Jenis barang } \\
\text { 8. Ketersediaan barang (stok) }\end{array}$ \\
\hline & Promosi & $\begin{array}{l}\text { Promosi penjualan adalah } \\
\text { rangsangan langsung yang } \\
\text { ditujukan kepada konsumen } \\
\text { untuk melakukan pembelian } \\
\text { (Peter \& Olson.2000:182) }\end{array}$ & $\begin{array}{l}\text { 9. } \text { Promosi penjualan } \\
\text { 10. Hadiah } \\
\text { 11. Diskon }\end{array}$ \\
\hline & Suasana Toko & $\begin{array}{l}\text { Gabungan unsur-unsur desain } \\
\text { toko, penerangan, toko, } \\
\text { komunikasi visual dan } \\
\text { merchandising (Ma'ruf, } \\
\text { 2006:201). }\end{array}$ & 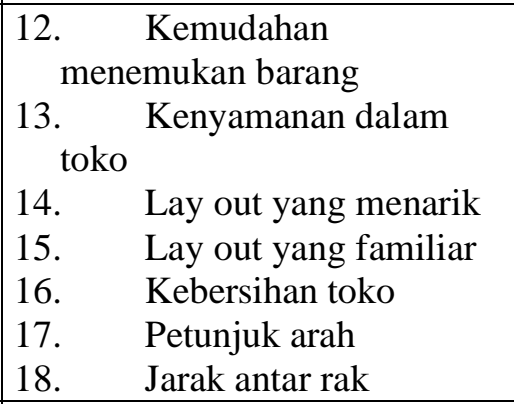 \\
\hline & Retail Service & $\begin{array}{l}\text { Aktifitas dan fasilitas yang } \\
\text { menyertai penjualan barang } \\
\text { dagang dengan } \\
\text { mempermudah } \\
\text { memuaskan } \\
\text { (Kotler: 2003). }\end{array}$ & $\begin{array}{ll}\text { 19. } & \text { Waktu operasional toko } \\
20 . & \text { Keramahan pramuniaga } \\
21 . & \text { Kecepatan pelayanan } \\
22 . & \text { Pengembalian barang } \\
\text { cacat } & \end{array}$ \\
\hline & Harga & $\begin{array}{l}\text { Harga adalah sejumlah uang } \\
\text { yang harus dibayar oleh } \\
\text { pelanggan untuk memperoleh } \\
\text { produk (Kotler \& Armstong. } \\
\text { 2001:73) }\end{array}$ & $\begin{array}{ll}23 . & \text { Kesesuaian harga } \\
\text { dengan kualitas } \\
\text { 24. } \quad \text { Keterjangkauan harga } \\
25 . \quad \text { Harga relatif murah }\end{array}$ \\
\hline
\end{tabular}


Dari operasionalisasi variabel di atas kemudian dikembangkan ke dalam rancangan penelitian seperti nampak di bawah ini,

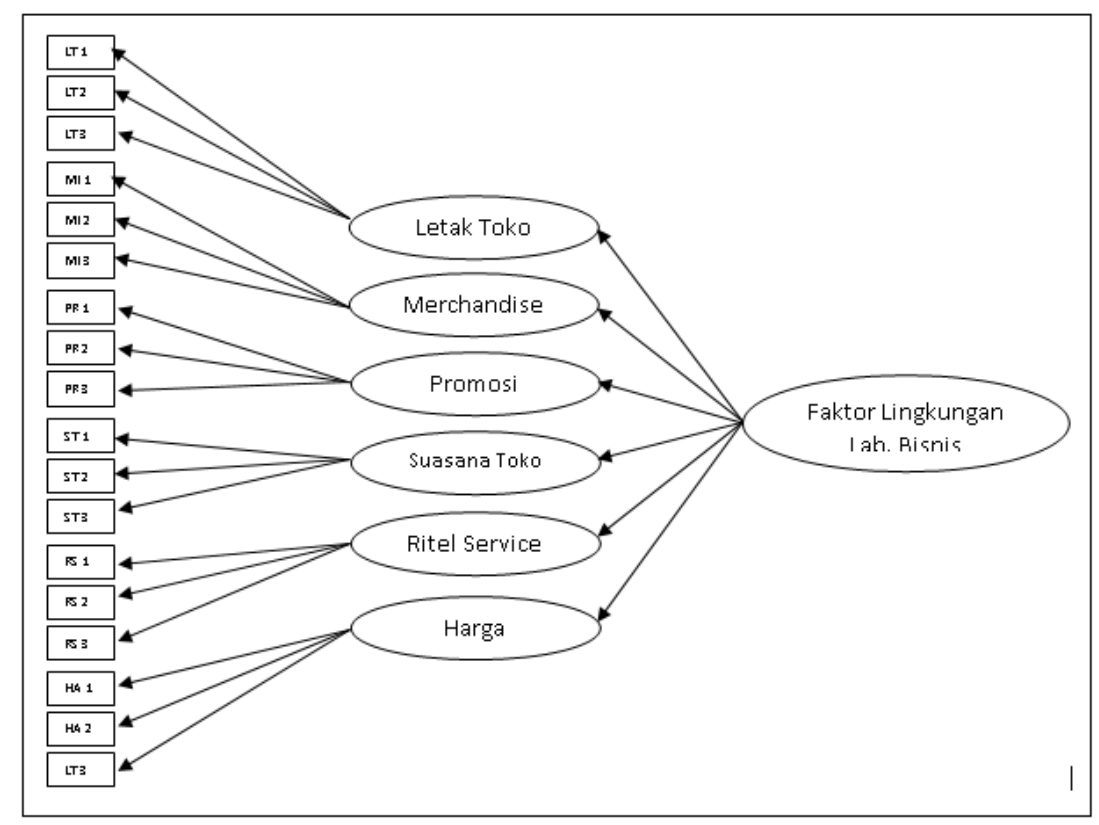

Gambar 2. Rancangan Penelitian

\section{Metode Analisis Data}

Dalam menganalisis data yang diperoleh menggunakan program IBM SPSS Statistic Data Editor 21.0, suatu perangkat lunak komputer yang biasa digunakan untuk perhitunganperhitungan statistik dalam penelitian. Teknik analisa yang digunakan adalah analisa frekuensi dananalisis faktoreksplorasi yang dihitung berdasarkan angka-angka yang diperoleh dari hasil pengolahan data penelitian.

1) Analisis Deskriptif Frekuensi

Analisis deskriptif frekuensi digunakan untuk pengolahan data mengenai profil responden yaitu jenis kelamin, usia, pekerjaan, penghasilan/bulan dan pertanyaan lainnya.

2) Exploratory Factor Analysis (EFA)

Metode analisis faktor menganalisis interaksi antarvariabel. Dalam analisis faktor, semua variabel berstatus independen. Analisis faktor juga berguna untuk mengidentifikasi struktur hubungan antar variabel atau antar responden, mencari dimensi laten yang mewakili variabel, dan mengurangi data (Simamora, 2005:105).Dalam penelitian ini, exploratory factor analysis digunakan untuk menganalisis faktor-faktor yang dominan di mata responden. Kelayakan analisis faktor dilakukan dengan menggunakan uji Kaiser-Mayer-Olkin (KMO). Nilai KMO berkisar antara 0 sampai dengan 1. Apabila nilai indeks berkisar antara 0,5 sampai dengan 1, maka analisis faktor layak untuk dilakukan. Apabila nilai KMO uji kurang dari 0,5, maka analisis faktor tidak layak dilakukan (Simamora, 2005:123). 


\section{Hasil Penelitian dan Diskusi}

Penelitian ini menghimpun data dari 161 orang pengunjung Lab. Bisnis secara acak yang memiliki profil sebagaimana yang ditunjukan Tabel 2.

Sementara itu analisis data pada penelitian ini menggunakan EFA untuk mengidentifikasi faktor-faktor utama yang menjelaskan kesamaan (communality) sekumpulan variabel dan mengidentifikasi faktor baru yang mungkin terbentuk berdasarkan korelasi (factor loadings) dan perbedaan (eigenvalue) yang dihasilkan masing-masing faktor.

Tabel 2. Profil Responden

\begin{tabular}{|c|c|c|c|}
\hline Profil & Kategori & Jumlah Responden & Persentase \\
\hline \multirow[t]{2}{*}{ Jenis Kelamin } & Laki-laki & 38 & 23.6 \\
\hline & Perempuan & 123 & 76.4 \\
\hline \multirow[t]{5}{*}{ Umur } & $\leq 20$ tahun & 64 & 39.7 \\
\hline & 21-25 tahun & 93 & 57.7 \\
\hline & 26-30 tahun & 4 & 2.6 \\
\hline & 31-35 tahun & 0 & 0 \\
\hline & $\geq 36$ tahun & 0 & 0 \\
\hline \multirow[t]{4}{*}{ Lama di POLBAN } & $<1$ tahun & 51 & 31.7 \\
\hline & $1-5$ tahun & 110 & 68.3 \\
\hline & 6-10 tahun & 0 & 0 \\
\hline & $>10$ tahun & 0 & 0 \\
\hline \multirow[t]{4}{*}{ Pengeluaran per bulan } & $<1$ juta & 94 & 58.4 \\
\hline & $1-2$ juta & 65 & 40.4 \\
\hline & 3-4 juta & 0 & 0 \\
\hline & $>4$ juta & 2 & 1.2 \\
\hline
\end{tabular}

Tahap awal sebelum dilakukan analisis faktor adalah dengan mengubah data yang berskala ordinal menjadi interval dengan menggunakan Method of Successive Interval (MSI). Metode suksesif interval merupakan proses mengubah data ordinal menjadi data interval. Data ordinal sebenarnya adalah data kualitatif atau bukan angka yang sebenarnya. Data ordinal menggunakan angka sebagai simbol data kualitatif. Karena penelitian ini menggunakan skala likert yang menghasilkan data ordinal, maka data tersebut harus diubah ke dalam bentuk interval agar bisa memenuhi persyaratan prosedur statistik selanjutnya. Adapun data berskala interval hasil olahan MSI dapat dilihat pada Lampiran VI. 
Tabel 3. Hasil Uji Anti-Image Correlation, KMO dan Bartlett's Test

\begin{tabular}{|c|c|}
\hline Item & Anti-Image Correlation \\
\hline 1 & 0.651 \\
\hline 2 & 0.666 \\
\hline 3 & 0.732 \\
\hline 4 & 0.814 \\
\hline 5 & 0.891 \\
\hline 6 & 0.854 \\
\hline 7 & 0.797 \\
\hline 8 & 0.835 \\
\hline 9 & 0.872 \\
\hline 10 & 0.660 \\
\hline 11 & 0.680 \\
\hline 12 & 0.885 \\
\hline 13 & 0.866 \\
\hline 14 & 0.910 \\
\hline 15 & 0.820 \\
\hline 16 & 0.843 \\
\hline 17 & 0.859 \\
\hline 18 & 0.704 \\
\hline 19 & 0.775 \\
\hline 20 & 0.811 \\
\hline 21 & 0.795 \\
\hline 22 & 0.875 \\
\hline 23 & 0.849 \\
\hline 24 & 0.804 \\
\hline 25 & 0.847 \\
\hline 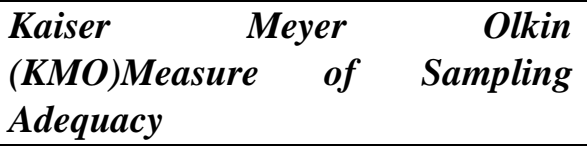 & 0.813 \\
\hline Bartlett's Test of Sphericity & $\begin{array}{ll}\text { Chi Square } & 1771.789 \\
d f & 300 \\
\text { Sig. } & 0.000\end{array}$ \\
\hline
\end{tabular}


Selanjutnya, perlu dipastikan kelayakan variabel-variabel yang ada pada penelitian ini untuk diuji dengan analisis faktor. Dalam tahap ini, ada dua hal yang perlu diperhatikan agar analisis faktor dapat dilaksanakan, yang pertama yaitu besaran nilai Barlett Test of Sphericity, yang digunakan untuk mengetahui apakah ada korelasi yang signifikan antar variabel, dan kedua adalah Keiser-Meyers-Oklin (KMO) Measure of Sampling Adequacy, yang digunakan untuk mengukur kecukupan sampel dengan cara membandingkan besarnya koefisien korelasi yang diamati dengan koefisein korelasi parsialnya. Hasil Bartlett's Test of Sphericity pada penelitian ini adalah 0.813 dengan nilai signifikansi 0.000 ( $\mathrm{p}<0.001)$, yang merupakan nilai minimum dalam penilaian kemungkinan kesalahan. Oleh karena itu, dapat disimpulkan bahwa instrumen pada penelitian ini sangat layak untuk digunakan dalam melakukan faktor analisis. Selanjutnya, kami menganalisis kelayakan data yang kami miliki untuk EFA dengan menggunakan KMO dan Anti-Image Correlation. Adapaun hasilnya menunjukan kesesuaian data untuk EFA dengan KMO bernilai 0.811 (> 0.05) dan rata-rata korelasi antar variabel diatas 0.650 sebagaimana yang diperlihatkan pada Tabel 3 yang menunjukkan bahwa kecukupan sampel termasuk kategori menengah.

Langkah berikutnya dalam analisis faktor adalah melakukan ekstraksi faktor terhadap seluruh variabel dalam penelitian yang berjumlah 25 item menggunakan metode ekstraksi Principal Component Analysis. Berdasarkan Tabel 4 terdapat tujuh komponen faktor dengan nilai kumulatif varians sebesar $67.029 \%$. Tujuh faktor utama ini dihasilkan berdasarkan proses ekstraksi faktor yang mengeliminasi variabel dengan eigenvalue kurang dari 1.0. Hasil ini berbeda dengan rancangan penelitian yang hanya menetapkan enam faktor sebagai komponen faktor lingkungan. Kemungkinan paling besar yang menyebabkan bertambahnya faktor ini disebabkan oleh adanya perbedaan konstruk antara beberapa variabel dalam satu faktor sehingga sulit diintrepretasikan dan dibutuhkan pembentukan satu faktor baru untuk mengakomodir variabel-variabel tersebut.

Tabel 4. Nilai Variance Setelah Ekstraksi dan Rotasi

\begin{tabular}{ccccccc}
\hline \multirow{2}{*}{ Item } & \multicolumn{2}{c}{ Extraction Sums of Squared Loadings } & \multicolumn{3}{c}{ Rotation Sums of Squared Loadings } \\
\cline { 2 - 7 } & Total & \% of Variance & Cumulative \% & Total & \% of Variance & Cumulative \% \\
\hline 1 & 6.922 & 27.688 & 27.688 & 2.942 & 11.769 & 11.769 \\
2 & 2.656 & 10.625 & 38.313 & 2.877 & 11.507 & 23.276 \\
3 & 2.061 & 8.243 & 46.556 & 2.756 & 11.022 & 34.298 \\
4 & 1.583 & 6.334 & 52.889 & 2.194 & 8.776 & 43.074 \\
5 & 1.327 & 5.307 & 58.197 & 2.183 & 8.731 & 51.805 \\
6 & 1.161 & 4.646 & 62.842 & 2.076 & 8.303 & 60.109 \\
7 & 1.047 & 4.186 & 67.029 & 1.730 & 6.920 & 67.029 \\
\hline
\end{tabular}

Extraction Method: Principal Component Analysis

Untuk memaksimalkan pengelompokan variabel maka dilakukan rotasi faktor menggunakan metode VARIMAX. Metode ini berusaha memaksimalkan jumlah variance dalam muatan faktor. Sebuah variabel bisa jadi mempunyai muatan faktor atau faktor loading yang rata-rata tinggi atau rata-rata rendah dalam setiap variabelnya. Metode VARIMAX 
berusaha untuk menjadikan muatan faktor menjadi tinggi atau mendekati 1 atau -1 pada salah satu faktor. Tabel 4 menunjukan nilai eigenvalue dan variance sebelum dan setelah rotasi. Korelasi antara faktor dengan variabel sebelum rotasi ditunjukkan oleh Tabel 5. Sebagaimana yang ditunjukkan oleh tabel tersebut, variabel-variabel yang terhimpun pada seluruh faktor dalam penelitian ini berada diatas batas minimum loading 0.40. Oleh karena itu, korelasi variabel-variabel tersebut dengan faktornya dapat dipertanggungjawabkan.

\section{Tabel 5. Faktor Lingkungan Setelah Rotasi}

\begin{tabular}{|c|c|c|c|c|c|c|c|}
\hline Item Ke- & Merchandise & $\begin{array}{c}\text { Promosi dan } \\
\text { Kemudahan } \\
\text { Belanja }\end{array}$ & Harga & $\begin{array}{c}\text { Keterse } \\
\text { diaan }\end{array}$ & $\begin{array}{c}\text { Kenyamanan } \\
\text { Belanja }\end{array}$ & $\begin{array}{l}\text { Retail } \\
\text { Service }\end{array}$ & $\begin{array}{c}\text { Tampilan } \\
\text { Toko }\end{array}$ \\
\hline 7 & .778 & & & & & & \\
\hline 6 & .761 & & & & & & \\
\hline 8 & .639 & & & & & & \\
\hline 5 & .609 & & & & & & \\
\hline 10 & & .897 & & & & & \\
\hline 11 & & .890 & & & & & \\
\hline 17 & & .596 & & & & & \\
\hline 9 & & .547 & & & & & \\
\hline 4 & & .463 & & & & & \\
\hline 24 & & & .851 & & & & \\
\hline 25 & & & .818 & & & & \\
\hline 23 & & & .774 & & & & \\
\hline 2 & & & & .877 & & & \\
\hline 3 & & & & .755 & & & \\
\hline 1 & & & & .710 & & & \\
\hline 19 & & & & -.068 & & & \\
\hline 18 & & & & & .649 & & \\
\hline 13 & & & & & .578 & & \\
\hline 14 & & & & & .449 & & \\
\hline 21 & & & & & & .776 & \\
\hline 20 & & & & & & .752 & \\
\hline 22 & & & & & & .587 & \\
\hline 15 & & & & & & & .714 \\
\hline 12 & & & & & & & .480 \\
\hline
\end{tabular}


Hal terakhir yang harus dilakukan dalam EFA adalah penamaan faktor yang terbentuk. Penamaan faktor ditentukan oleh muatan faktor yang dijelaskan oleh faktor terhadap setiap variabel. Sebagaimana terlihat pada Tabel 5, dari 25 variabel yang dianalisis, terbentuklah faktor yang terdiri dari tujuh faktor, yaitu:

1. Faktor 1 yang diberi nama 'merchandise' terdiri dari ítem ketujuh (jenis barang), keenam (kualitas barang), kedelapan (ketersediaan barang) dan kelima (kualitas barang).

2. Faktor 2 yang diberi nama 'promosi dan kemudahan berbelanja' terdiri dari ítem kesepuluh (hadiah), kesebelas (diskon), ketujuh belas (petunjuk arah), kesembilan (promosi penjualan) dan keempat (fasilitas).

3. Faktor 3 yang diberi nama 'harga' terdiri dari ítem kedua puluh empat (keterjangkauan harga), kedua puluh lima (harga relatif murah) dan kedua puluh tiga (kesesuaian harga dengan kualitas barang).

4. Faktor 4 yang diberi nama 'ketersediaan' terdiri dari ítem kedua (kemudahan menjangkau toko), ketiga (lokasi yang strategis), kesatu (berada di lokasi yang mudah dilewati) dan kesembilan belas (waktu operasional).

5. Faktor 5 yang diberi nama 'kenyamanan berbelanja' terdiri dari ítem kedelapan belas (jarak antar rak), ketiga belas (kenyamanan dalam toko) dan keempat belas (lay out yang menarik).

6. Faktor 6 yang diberi nama 'retail service' terdiri dari ítem kedua puluh satu (kecepatan pelayanan), kedua puluh (keramahan pelayanan) dan kedua puluh dua (fasilitas retur barang cacat).

7. Faktor 7 yang diberi nama 'tampilan toko' terdiri dari ítem kelima belas (lay out yang familiar), kedua belas (kemudahan menemukan barang) dan keenam belas (kebersihan toko).

Faktor kedua diputuskan untuk diubah namanya menjadi 'promosi dan kemudahan berbelanja' karena mendapatkan dua variabel baru yaitu petunjuk arah dan fasilitas. Faktor keempat disesuaikan namanya menjadi 'ketersediaan' karena mengandung dua komponen dalam satu faktor yaitu lokasi dan waktu operasional. Adapun 'suasana toko' dipecah menjadi dua faktor yang berbeda yaitu 'kenyamanan berbelanja' dan 'tampilan toko'.

\section{Kesimpulan dan Saran Kesimpulan}

Hasil penelitian ini menunjukkan bahwa faktor lingkungan Lab. Bisnis terdiri dari tujuh dimensi atau faktor yang meliputi merchandise, promosi dan kemudahan berbelanja, harga, ketersediaan, kenyamanan berbelanja, retail service dan tampilan toko.

Faktor merchandise terdiri dari jenis barang, kualitas barang, ketersediaan (stok) barang dan kualitas barang yang tersedia di toko.Faktor promosi dan kemudahan berbelanja terdiri dari hadiah, diskon, promosi penjualan yang ditawarkan, petunjuk arah di dalam toko dan fasilitas yang memadai untuk pengunjung. Faktor harga terdiri dari keterjangkauan harga, penetapan harga yang relatif murah dan kesesuaian harga dengan kualitas barang.Faktor ketersediaan terdiri dari kemudahan konsumen dalam menjangkau toko, lokasi toko yang strategis, lokasi toko yang berada di tempat yang mudah dilewati konsumen dan waktu 
operasional (jam buka dan tutup) toko yang sesuai dengan kebutuhan konsumen.Faktor kenyamanan berbelanja terdiri dari jarak antar rak yang memadai untuk konsumen berlalu lalang, kenyamanan dalam toko dan lay out toko yang menarik.Faktor retail service terdiri dari kecepatan pelayanan, keramahan para pramuniaga dan fasilitas pengembalian barang yang cacat.Sementara itu faktor terakhir yaitu tampilan toko terdiri dari lay out toko yang familiar, kemudahan konsumen dalam menemukan barang yang dicari dan kebersihan toko yang terawat.

\section{Saran}

Analisis dalam penelitian ini dilakukan dengan pendekatan EFA. Pendekatan ini memungkinkan peneliti untuk menguji validitas konstruk melalui pengamatan terhadap korelasi antar konstruk secara dimensional. Namun temuan dalam penelitian ini tentu perlu diuji kembali oleh penelitian-penelitian lanjutan dengan metode yang berbeda seperti misalnya confirmatory factor analysis (CFA).

\section{Daftar Pustaka}

Abdullah, Ali. (Desember 2007). Pasar Ritel 2008 Tetap Menjanjikan. Diambil 20 Mei 2008 dari http://aliasabdullah.blogspot.com

Baker, Bruce D., Margaret Terry Orr, and Michelle D. Young (2009) Educational Administration Quarterly: Academic Drift, Institutional Production, and Professional Distribution of Graduate Degrees in Educational Leadership, Vol 43, N0 3: 279-318.

Belch, Michael A \& George E. Belch (2004) Introduction to Advertising \& promotion: An Integrated Marketing Communication Perspective Ninth Edition. USA: Irwin.

Bitta, A.J.D., \& David, L.L. (1993). Customer Behavior Concept and Application (4 ${ }^{\text {th }}$ ed). Singapore: McGraw-Hill International.

Dikti (1996) Kerangka Pengembangan Pendidikan Tinggi Jangka Panjang (KPPTJP 19962005).

Dikti (2010), Rencana Strategis Kementrian Pendidikan Nasional 2010-2014.

Ghozali, Imam, (2008) Model Persamaan Struktural, Konsep dan Aplikasi Dengan Program AMOS 16.0, Semarang: Badan Penerbit Universitas Diponegoro.

Griffin, J. (2002). Customer Loyalty - How To Earn It, How To Keep It. Singapore:Lexington Bodes.

Haksever, Render, Russel, and Murdick (2000) Service Management and Operations, New Jersey: Prentice Hall.

Hawkins, Motherbough, \& Best (2007) Consumer Behavior. New York: Mc Graw Hill.

Hurriyati, Dr. Ratih, M.Si. (2008). Bauran Pemasaran dan Kepuasan Konsumen. Bandung: ALFABETA.

Irawan, Handi. (2002). 10 Prinsip Kepuasan Pelanggan. Jakarta: Alex Media Kompetindo.

Kotler, Philip \& Amstrong, Gary. (2008). Principle of Marketing (9 ${ }^{\text {th }}$ Edition). New Jersey: Prentice Hall. 
Kumar, Archana, (2010). The Impact of Store Environment on Consumer Evaluation and Behavior toward Single-Brand Apparel Retailers. Journal of Tennessee University, 3 (4).

Ma’ruf, Hendri. (2006). Pemasaran Ritel. Jakarta: PT.Gramedia Pustaka Utama.

Malhotra, Naresh K. (2004). Marketing Research, $4^{\text {th }}$ ed an Applied Orientation. New Jersey: Prentice Hall.

Manning, Gerald L \& Barry, L Reece. (2004). Selling Today, Building Quality Partnership, (6th $E d)$. New Jersey: Prentice Hall.

Nahla Al-Nazer and Laith Alrubaiee (2010). Investigate the impact of relationship marketing orientation on customer loyalty: the customer's perspective. International Journal of Marketing Studies. 2.1 (May 2010) p155.

Nazir, Moh. (2003). Metode Penelitian. Jakarta: Ghalia Indonesia.

Oliver, R.L. (1997). Satisfaction A Behavioral Perspective on The Consumer.

Omar, O.E. (1999). Retail Marketing. Harlow, England: Perason Education.

Parasuraman, A., Zeithaml, V.A, Berry, L.L (1998) Journal of Retailing, Vol. 64, pp. 12-40, SERVQUAL: A Multiple-Item Scale for Measuring Customer Perception of Service.

Peter, J. Paul dan Jerry C. Olson. (2000). Perilaku Konsumen dan Strategi Pemasaran Edisi 4 Jilid 2. Jakarta:PT.Erlangga

Rangkuti, Freddy. (2002). Riset Pemasaran. Jakarta: PT.Gmamedia Pustaka Utama.

Simamora, Bilson. (2005). Analisis Multivariat Pemasaran. Jakarta: PT. Gramedia Pustaka Utama.

Sugiama, A. Gima. (2008). Metode Riset Bisnis dan Manajemen. Bandung: Guardaya Intimarta

Zeithalm, Valarie A. and Bitner, Mary (1996) Service Marketing, New York: The McGraw Hill Companies. 